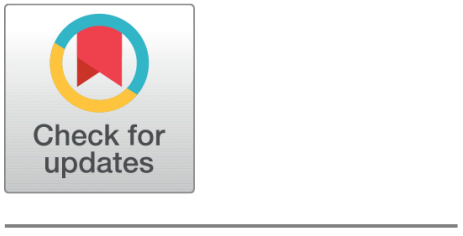

OPEN ACCESS

Received: 05.08.2020

Accepted: 02.10 .2020

Published: 13.10 .2020

Editor: Dr. Natarajan Gajendran

Citation: Pokharkar OH, Lalsare KR, Mohite AS, Chavan SB (2020) Design and implementation of a low cost electric bike for domestic purposes. Indian Journal of Science and Technology 13(37): 3843-3849. https ://doi.org/10.17485/IJST/v13i37.1297

*Corresponding author.

Tel: 91 - 9975490278

sbc_tech@unishivaji.ac.in

Funding: None

Competing Interests: None

Copyright: (c) 2020 Pokharkar et al. This is an open access article distributed under the terms of the Creative Commons Attribution License, which permits unrestricted use, distribution, and reproduction in any medium, provided the original author and source are credited.

Published By Indian Society for Education and Environment (iSee)

ISSN

Print: 0974-6846

Electronic: 0974-5645

\section{Design and implementation of a low cost electric bike for domestic purposes}

\author{
Omkar H Pokharkar ${ }^{1}$, Kshitij R Lalsare ${ }^{1}$, Anuja S Mohite ${ }^{1}$, \\ Shamkumar B Chavan ${ }^{2 *}$
}

1 Student, B. Tech Electronics \& Communication Technology program, Department of Technology, Shivaji University, Kolhapur, India

2 Assistant Professor (project guide), Department of Technology, Shivaji University, Kolhapur, 416004, Maharashtra, India. Tel.: 91- 9975490278

\section{Abstract}

Aim/ Objectives: The aim of this research work is to design and implement a low cost electric bike to use for day to day activities, to analyze the mileage of the bike for every charging per hour. Method: Initially the model of $\mathrm{H}$ bridge driver circuitry is created to drive the BLDC motor in Proteus simulation software. PWM pulses are fed to $\mathrm{H}$-bridge driver circuitry and response of the BLDC motor is studied. The speed control mechanism of BLDC motor driver is studied in simulation. Then the $\mathrm{H}$-bridge converter circuitry is designed and developed to drive the BLDC motor. The assembly of BLDC motor and tyre is selected which act as rear wheel. The system is designed around Arduino microcontroller. Lithium ion battery is used to supply power. Program is developed for Arduino Uno microcontroller to generate PWM pulses which are fed to $\mathrm{H}$-bridge driver. The performance of the BLDC motor driver is analyzed. After precise control of the motor and tyre assembly, the other subsystems like speedometer, indicator, accelerator, horn, braking system etc. are developed and tested. Motor controller and status monitoring controller acts in coordination due to which in any faulty or abnormality situation both interacts with each other to take necessary action. Finally the mechanical assembly and chassis is designed and developed. Findings: The bike developed in this work is found to be useful for day to day domestic uses. The maximum speed of 40 $\mathrm{km} / \mathrm{hr}$ is achieved and upon charging for nearly 3 hours it travels around 70 $\mathrm{km}$.

Keywords: Low cost E-bike; electric vehicle; BLDC motor driver; microcontroller based E-bike

\section{Introduction-}

Due to the petroleum crisis and polluting effects in world, nowadays trend is seen in automobile industry to switch to electric vehicles. Efforts are being taken on performance improvement of electric vehicles and considerable success is also obtained. Fuzzy logic based system is described to determine the range of the electric vehicle ${ }^{(1)}$. Battery, super-capacitor and fuel cell are used as energy sources and three non-linear 
controllers are modeled and their performance is compared ${ }^{(2)}$. Synchronous buck converter with intelligent system is proposed for charging the electric bikes. PSIM based simulation and implementation is discussed ${ }^{(3)}$. Proportion assisted power controller and fuzzy logic based controllers are designed and compared which refers current speed and pedal torque to determine motor torque. Fuzzy logic controller found to be provided stable speed ${ }^{(4)} .8$ Bit microcontroller based electronic system is designed to control the BLDC motor for e-bike ${ }^{(5)}$. Different methods to control BLDC motor, load torque calculation etc. are discussed ${ }^{(6)}$. Design of E-bike is discussed in ${ }^{(7)}$. A dual output converter having $48 \mathrm{~V}$ input along with output of $5 \mathrm{~V}$ and $12 \mathrm{~V}$ is proposed for ebike $^{(8)}$. PID based braking system is proposed for e-bike ${ }^{(9)}$. Flux synchronous reluctance machine having outer rotor is designed and analyzed for use in e-bike ${ }^{(10)}$. The SRM motor with modified stator is proposed for e-bikes ${ }^{(11)}$. Electromechanical bike is presented which works electric mode and in IC engine mode ${ }^{(12)}$. In the work presented in this paper design and implementation aspects of electric vehicle is described. The prototype is developed in laboratory and tested successfully.

\section{Materials and Method}

In initial phase the facilities to be given for the bike are planned, the accessories to be used are determined; the structure of the bike is decided. With this in mind BLDC motor is selected and priority is given to the assembly having tyre and BLDC motor. After this simulation is performed in Proteus software to drive the BLDC motor and experimentation is done, the pattern of the waveforms to be applied to BLDC motor is studied. Then actual hardware is implemented and experimentation is performed. After getting precise control and speed regulation of the motor actual hardware is developed and other accessories are interfaced.

\subsection{System design and development}

The presented hardware system is developed around Arduino Uno development board. Two Arduino Uno boards are used, one monitors and regulates the $3 \phi$ BLDC motor by referring the input from accelerator and hall effect sensor, here it is called as motor controller. Another Arduino based system monitors and displays the parameters like bike speed, battery voltage and current, main key etc.it is called as status monitoring controller. Both motor controller and status monitoring controller acts in coordination with each other. When supply is switched ON both controllers are activated however status monitoring controller first checks the battery electrical parameters, if these parameters are above required threshold then it signals the motor controller. Motor controller then monitors the signal of throttle valve which is connected to accelerator. Based on the angular movement of the accelerator, the throttle generates the electrical signal which is fed to the motor controller. Motor controller generates pulses of desired duty cycles which are fed to MOSFET drivers. MOSFET driver pulses are applied to $3 \phi$ BLDC motor through $3 \phi$ half bridge converter. For code generation the motor controller takes reference of Hall effect sensors which are fitted in BLDC motor. Figures 1 and 3 shows system block diagrams while Figures 2 and 4 show the flow charts.

Two different microcontrollers are used which works in coordination. One microcontroller monitors the status of battery parameters, if they are above threshold then it displays the status on LCD, it also counts and displays the speed of bike, stores and displays the distance travelled in the permanent memory chip. Resistive voltage divider network is used to sense battery voltage and current with suitable scale factor in program. If battery parameters are within the range and no fault is received by the fault sensing sensors then it signals the motor driving controller. The motor driving controller senses the throttle position via potentiometric principle based sensor and accordingly accelerates the bike. For this is switches the MOSFETs of half bridge controller while sensing the output of Hall sensors. This rotates the BLDC motor hence desired speed is obtained to the bike. The $\mathrm{n}$ channel MOSFET 75N75 is used in this application with suitable heat sink. IR 2101 MOSFET driver IC is used to drive the MOSFETs. Mechanical braking assembly is used to control the speed along with deceleration of accelerator handle.

The assembly of 3 phase BLDC motor and tyre is used as rear wheel which also drives the front wheel. BLDC uses electrical commutation and it consists of 3 phase stator and magnets on rotor. The rotor position is sensed using Hall effect sensors. Field is excited in stator windings and the rotor field follows it. The position of the rotor is sensed by the hall effect sensors. Figure 5 shows circuitry for converter and motor driver. Table 1 shows states of transistors and sensor sensing mechanisms for generation of driving codes. Figure 6 shows voltage pulses across BLDC motor. 


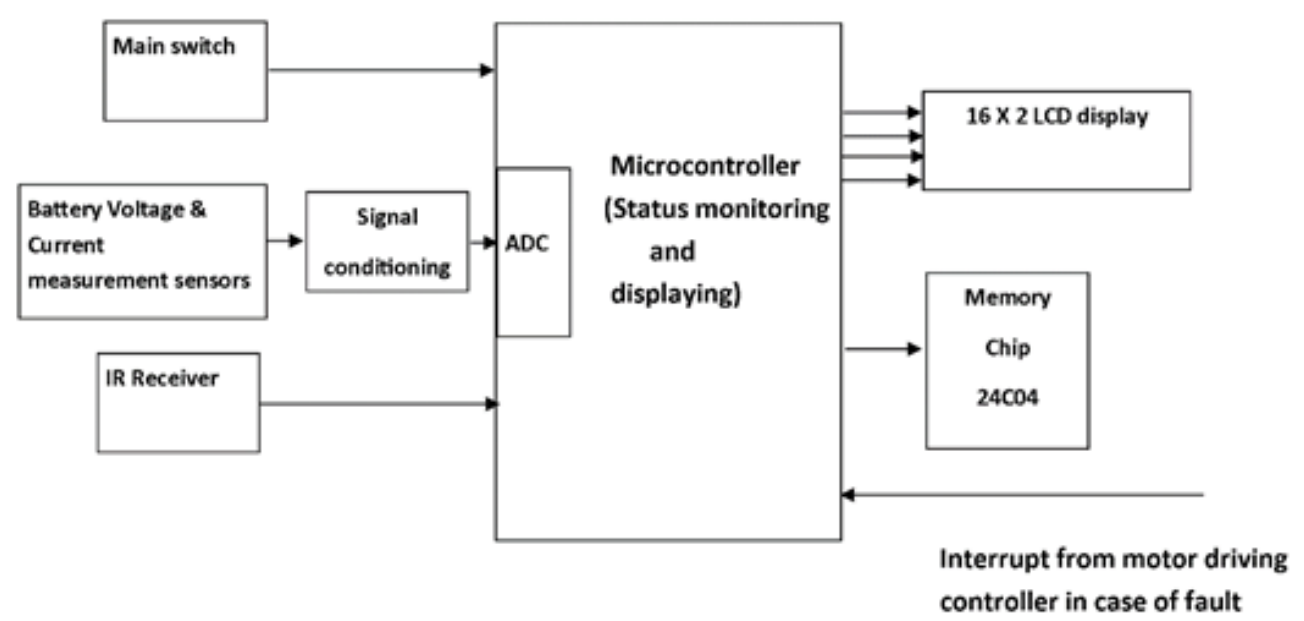

Fig 1. Condition monitoring microcontroller subsystem

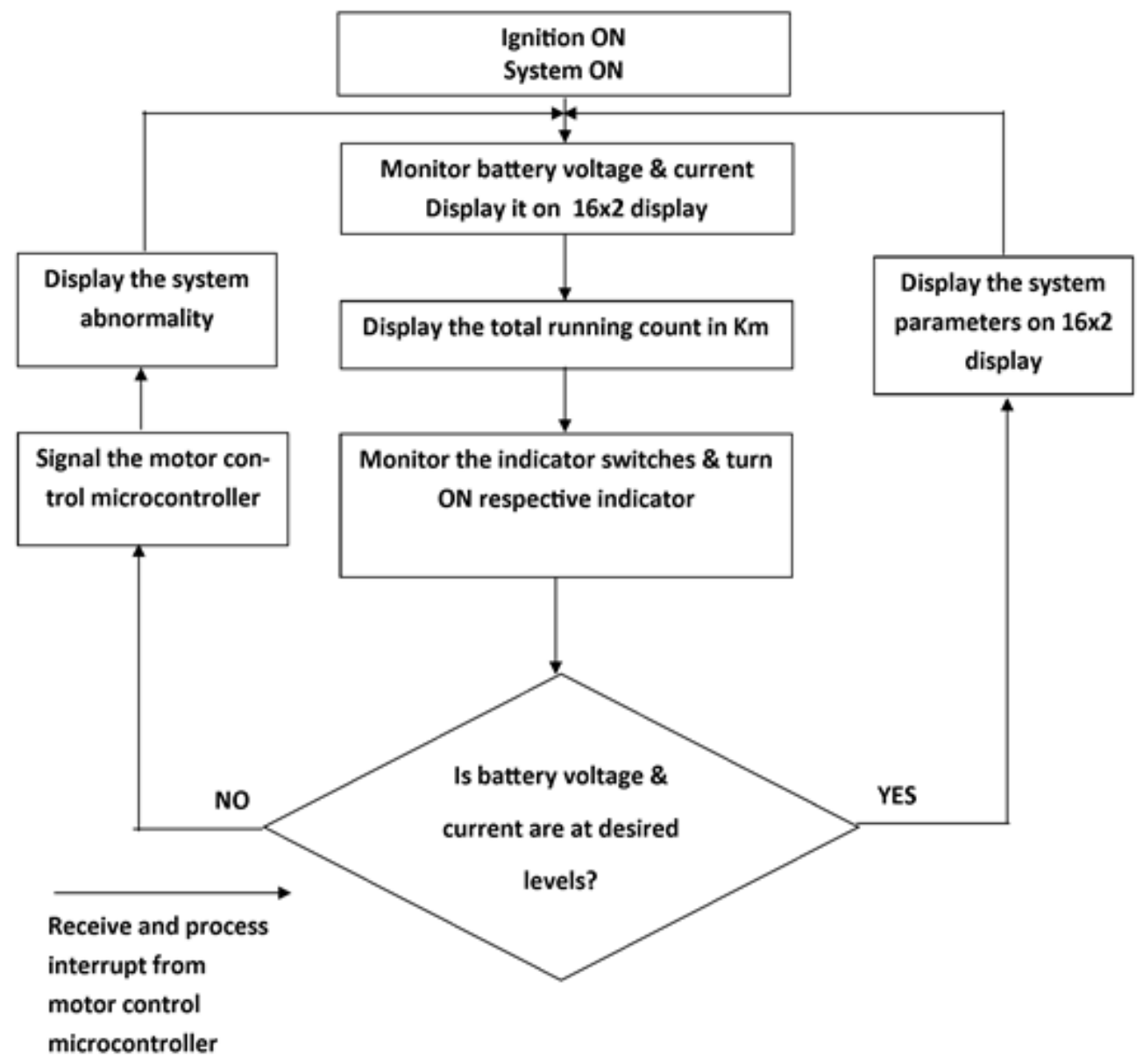

Fig 2. Flowchart for the condition monitoring microcontroller subsystem 


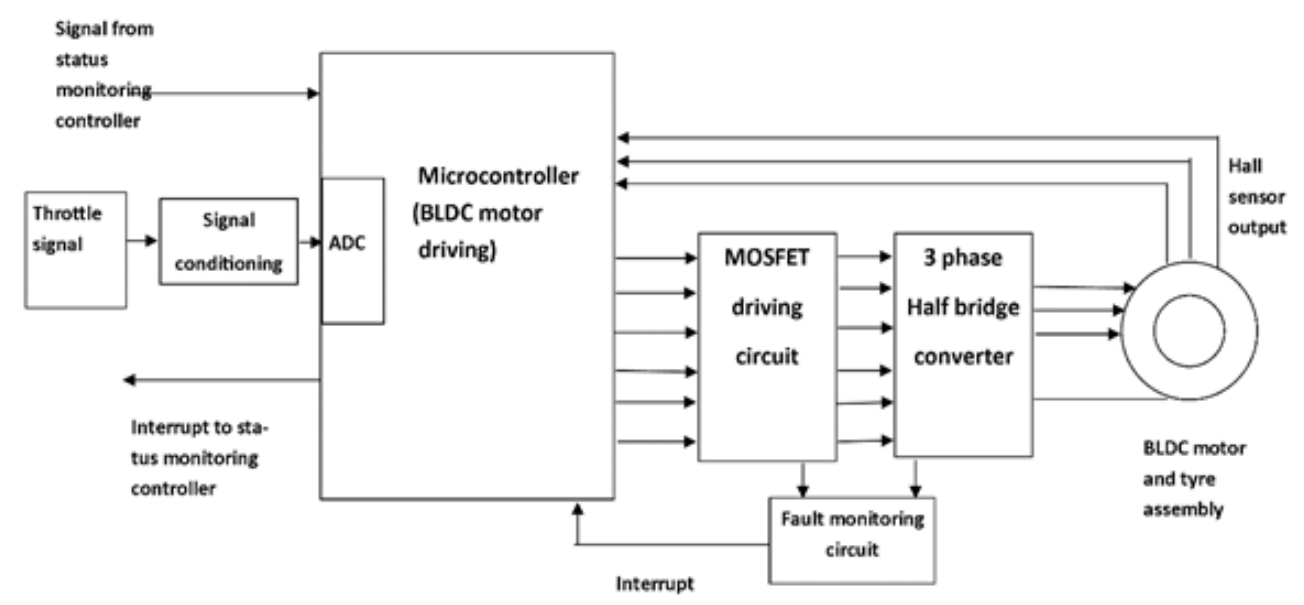

Fig 3. Speed control subsystem

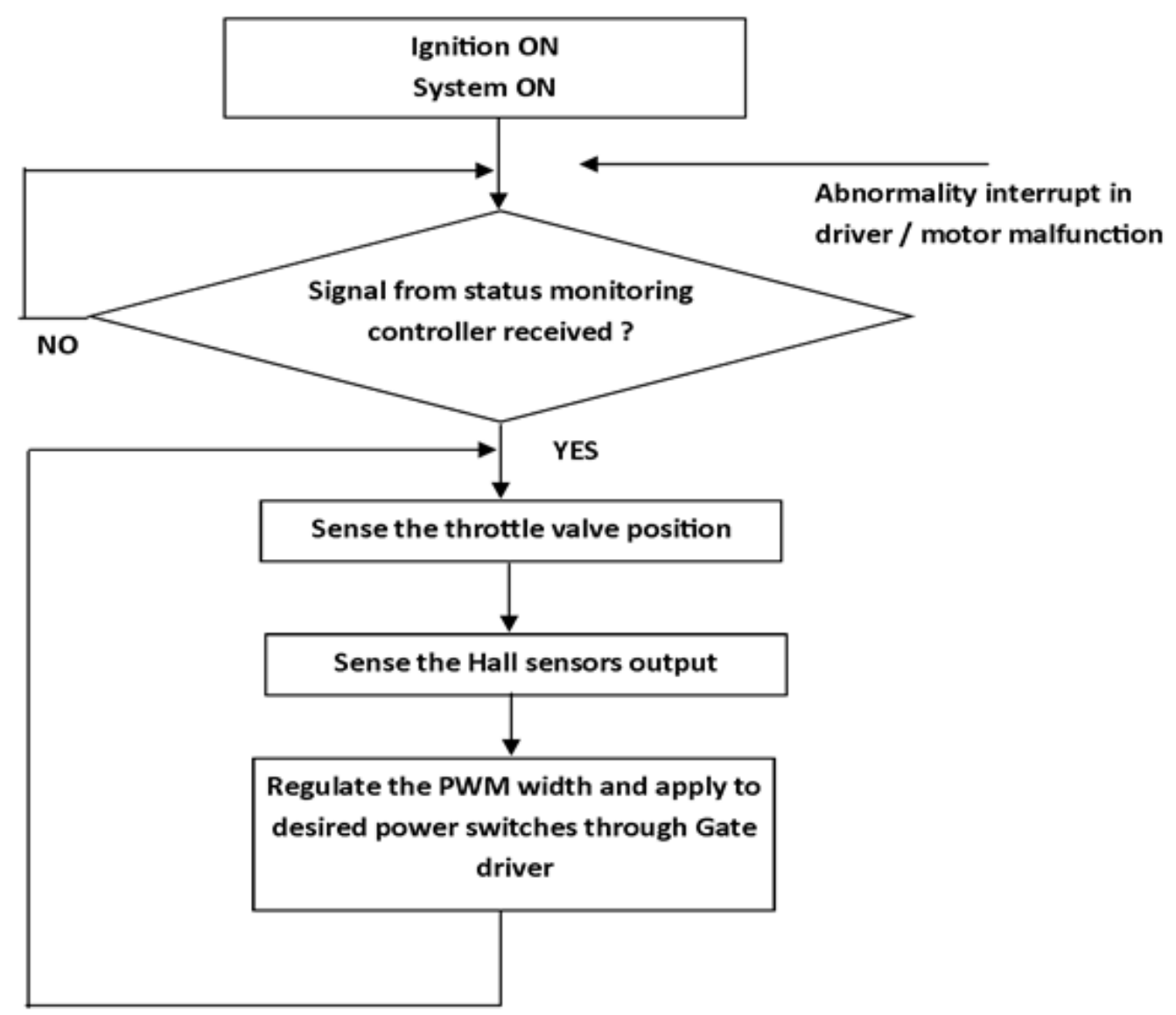

Fig 4. Flowchart for speed control subsystem 


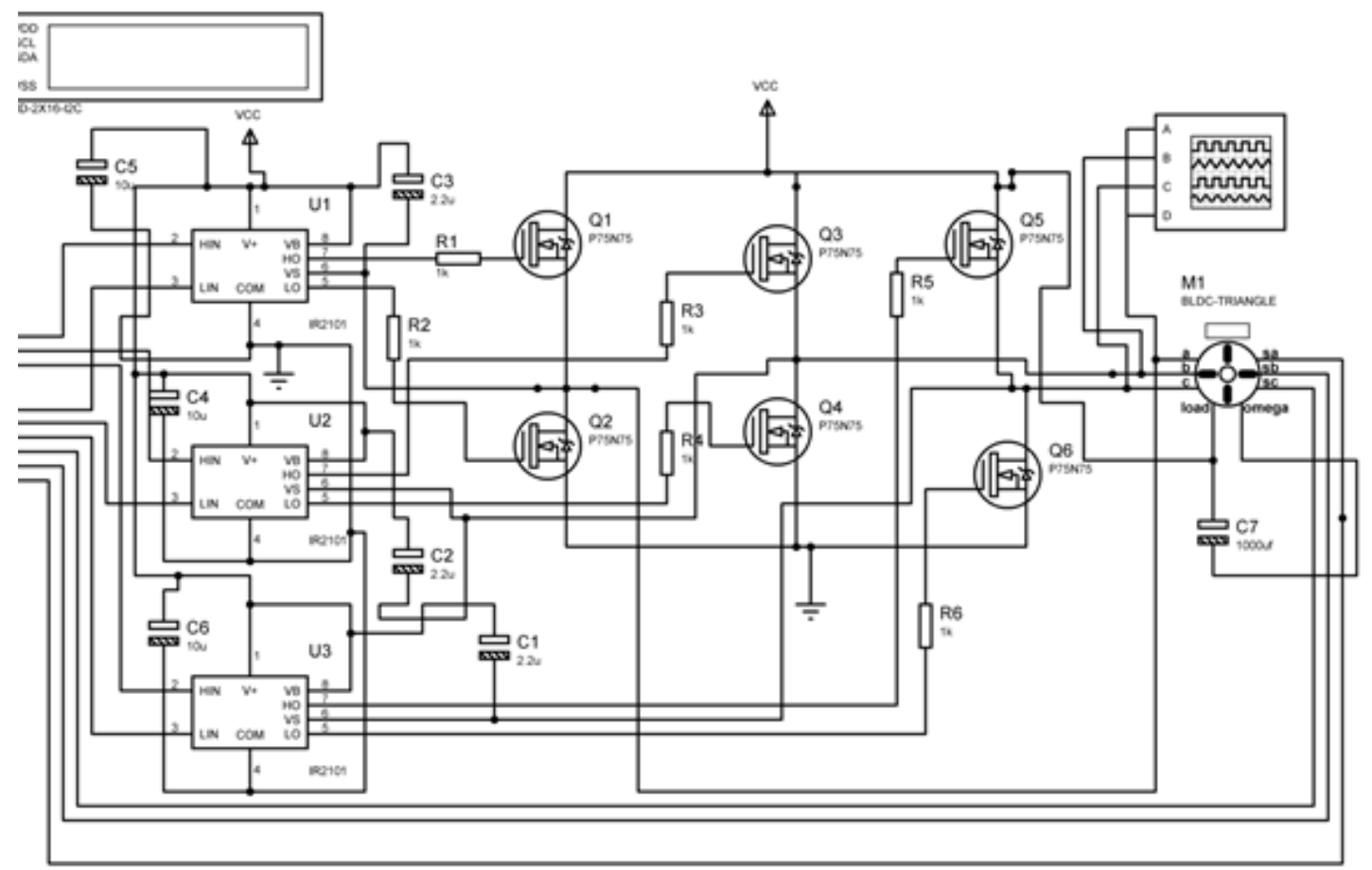

Fig 5. Motor driver and converter circuitry

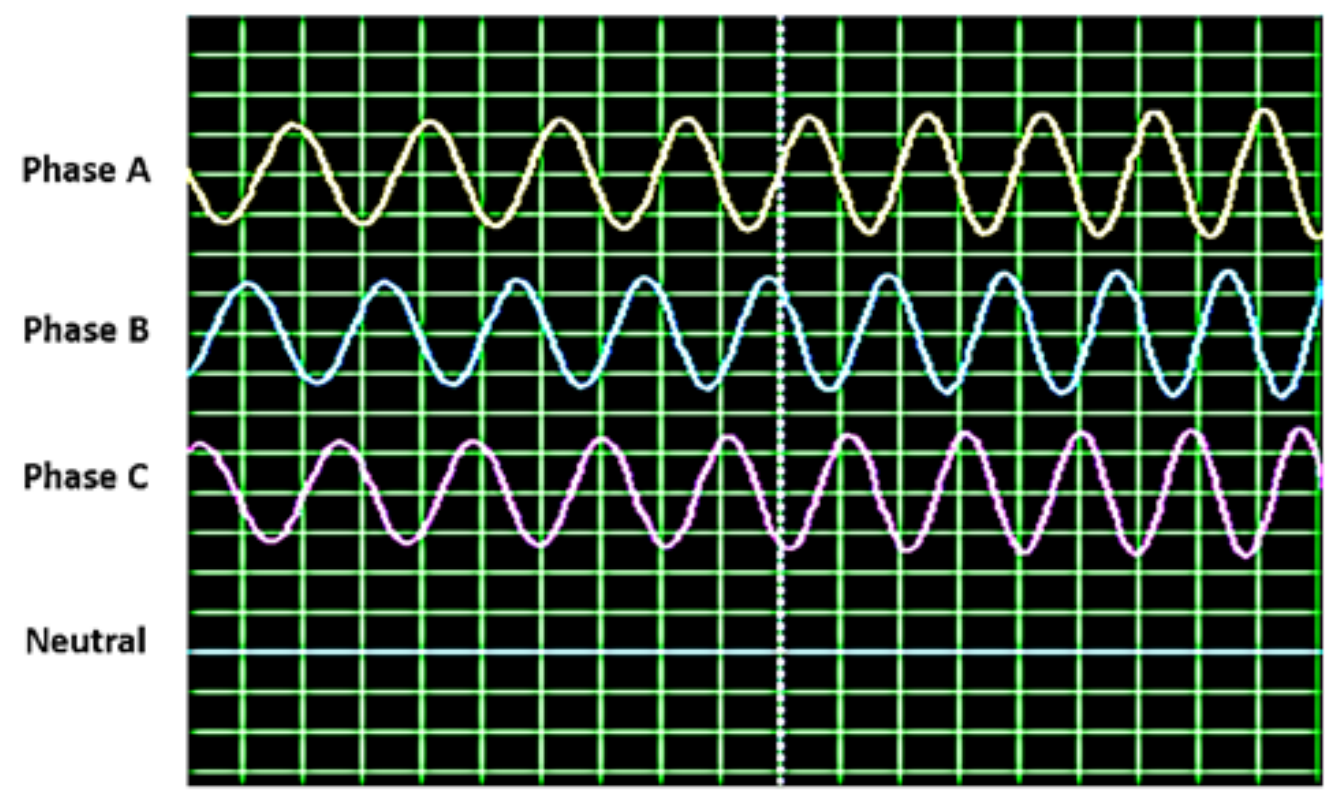

Fig 6. Voltage pulses appearing across BLDC motor 
Table 1. Transistor states for driving the BLDC motor

\begin{tabular}{|c|c|c|c|c|c|c|c|}
\hline \multirow{2}{*}{ Steps } & \multicolumn{3}{|c|}{ Phases } & \multicolumn{3}{|c|}{ Hall sensor Output } & \multirow{2}{*}{$\begin{array}{l}\text { ON } \\
\text { Transistors }\end{array}$} \\
\hline & $\mathbf{A}$ & B & $\mathrm{C}$ & 1 & 2 & 3 & \\
\hline 1 & Negative & Positive & Neutral & $\mathrm{H}$ & $\mathrm{L}$ & $\mathrm{H}$ & Q1,Q6 \\
\hline 2 & Negative & Neutral & Positive & $\mathrm{H}$ & $\mathrm{L}$ & $\mathrm{L}$ & Q3,Q4 \\
\hline 3 & Neutral & Negative & Positive & $\mathrm{H}$ & $\mathrm{H}$ & $\mathrm{L}$ & Q3,Q5 \\
\hline 4 & Positive & Negative & Neutral & $\mathrm{L}$ & $\mathrm{H}$ & $\mathrm{L}$ & Q1,Q5 \\
\hline 5 & Positive & Neutral & Negative & $\mathrm{L}$ & $\mathrm{H}$ & $\mathrm{H}$ & Q2,Q4 \\
\hline 6 & Neutral & Positive & Negative & $\mathrm{L}$ & $\mathrm{L}$ & $\mathrm{H}$ & Q2,Q6 \\
\hline
\end{tabular}

\section{Results and discussions}

The main concern in design of electric bike is the motor driving converter. It should be designed considering the reliability aspects. For reliability improvement following precautions must be taken:

1. Power switches i.e. MOSFET or IGBT should be of suitable rating. Heat sinks of appropriate dimensions should be selected.

2. Gate driving circuitry of higher reliability should be selected.

3. Power line paths should be of sufficient width.

4. Battery charging circuitry should charge the battery in proper manner for its long duration survival.

5. Status monitoring circuits, indicators should be connected to converter and battery.

6. MCBs/ fuses should be connected at suitable places to ensure SC protection.

The system parameters are given in Table 2.

Table 2. System parameters

\begin{tabular}{ll}
\hline Parameters & Value \\
\hline Battery Voltage & $48 \mathrm{~V}$ \\
Battery Ah & $11 \mathrm{Ah}$ \\
Mileage & $70 \mathrm{~km}$ for fully charged battery \\
Maximum speed & $40 \mathrm{~km} / \mathrm{Hr}$ \\
Weight & $30 \mathrm{Kg}$ \\
Approximate cost including batteries & $453 \mathrm{USD}$ \\
Weight carrying capacity & $80 \mathrm{Kg}$ \\
\hline
\end{tabular}

\section{Conclusions and future scope}

Electric bikes are useful and can be used for short distance travelling. They can satisfy the travelling need within few $\mathrm{km}$ areas. Their speed can be regulated precisely. However, the present challenge is increment in mileage per unit charge of a battery so that they can be used for long distance travelling. Implementation of charging stations and more importantly fast charging of batteries without affecting their life span are some of the challenging tasks in E- vehicle implementations. The reliable design of converter is another important issue of focus. It is recommended to keep different controllers like for fault sensing and motor control. In case of any fault like component damage during runtime, the respective controller will interact with motor controller to take required action. This will also enhance the safety while travelling.

\section{Acknowledgement}

The authors are thankful to Embedded systems and VLSI design laboratory of Electronics and Communication Technology program of Department of Technology, Shivaji University, Kolhapur for providing necessary resources for successful implementation of prototype of E-bike. 


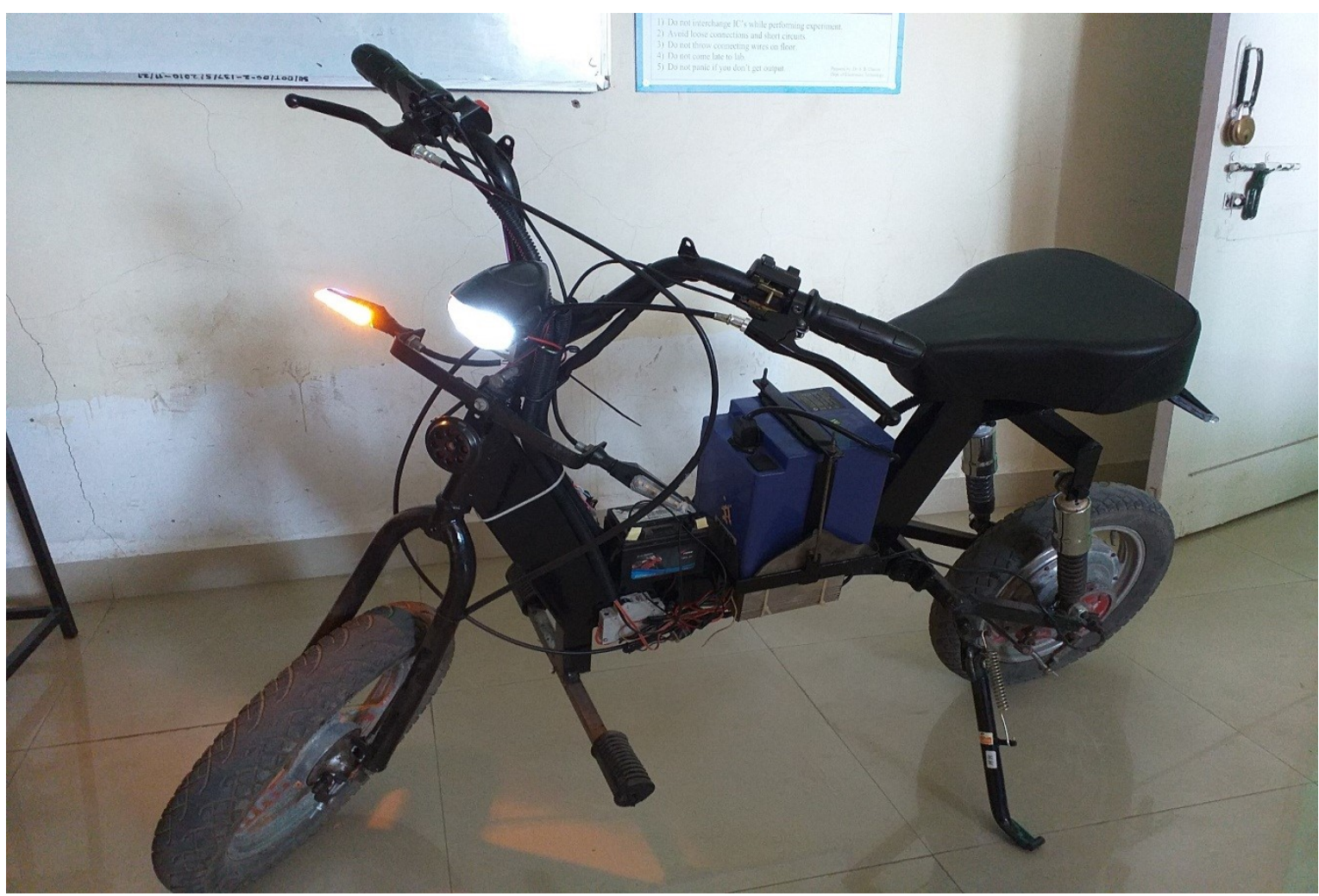

Fig 7. Prototype of E-bike developed in Laboratory

\section{References}

1) Çeven S, Albayrak A, Bayır R. Real-time range estimation in electric vehicles using fuzzy logic classifier. Computers \& Electrical Engineering. $2020 ; 83$. Available from: https://dx.doi.org/10.1016/j.compeleceng.2020.106577.

2) Rahman AU, Ahmad I, Malik AS. Variable structure-based control of fuel cell-supercapacitor-battery based hybrid electric vehicle. Journal of Energy Storage. 2020;29. Available from: https://dx.doi.org/10.1016/j.est.2020.101365.

3) Uddin MR, Tasneem Z, Annie SI, Salim KM. A high capacity synchronous buck converter for highly efficient and lightweight charger of electric easy bikes. In: and others, editor. International Conference on Electrical, Computer and Communication Engineering (ECCE). 2017;p. 392-395. Available from: https://doi.org/10.1109/ECACE.2017.7912936.

4) Lee J, Jiang J, Sun Y. Design and simulation of control systems for electric-assist bikes. In: and others, editor. IEEE 11th Conference on Industrial Electronics and Applications (ICIEA). 2016;p. 1736-1740. Available from: 1https://doi.org/10.1109/ICIEA.2016.7603866.

5) Dumitrache F, Carp MC, Pana G. E-bike electronic control unit. In: IEEE 22nd International Symposium for Design and Technology in Electronic Packaging (SIITME). 2016;p. 248-251. Available from: https://doi.org/10.1109/SIITME.2016.7777288.

6) Gromba J. Torque Control of BLDC Motor for Electric Bicycle. In: and others, editor. International Symposium on Electrical Machines (SME). 2018. Available from: https://doi.org/10.1109/ISEM.2018.8442987.

7) Reddy NPK, Prasanth KVSSV. Next generation electric bike E-bike. In: and others, editor. IEEE International Conference on Power, Control, Signals and Instrumentation Engineering. 2017;p. 2280-2085. Available from: https://doi.org/10.1109/ICPCSI.2017.8392123.

8) Jung DY. 48-to-5/12 V dual output DC/DC converter for high efficiency and small form factor in electric bike applications. In: and others, editor. IEEE Electrical Design of Advanced Packaging and Systems Symposium (EDAPS);vol. 1. 2017;p. 1-3. Available from: https://doi.org/10.1109/EDAPS.2017. 8276975.

9) Lin C, Chen E, Chen Y, Liu M. Advanced driving/braking control design for electric bikes. In: and others, editor. 12th IEEE Conference on Industrial Electronics and Applications (ICIEA). 2017;p. 1254-1259. Available from: https://doi.org/10.1109/ICIEA.2017.8283031.

10) Inte RA, Jurca FN. A novel synchronous reluctance motor with outer rotor for an electric bike. In: and others, editor. International Conference and Exposition on Electrical and Power Engineering (EPE). 2016;p. 213-218. Available from: https://doi.org/10.1109/ICEPE.2016.7781335.

11) Gabor R, Kowol M, Kołodziej J, Mynarek P. Steady State Analysis of Switched Reluctance Motor with Modified Geometry of the Stator Designed for an Electric Bike. In: and others, editor. International Symposium on Electrical Machines (SME). 2018;p. 1-5. Available from: https://doi.org/10.1109/ISEM. 2018.8442835 .

12) Nagendran R, Kumar K. Hybrid electric bike with three speed transmission system an energy efficient bike for next generation. Computer Engineering and Technology. 2010;p. 133-135. Available from: https://doi.org/10.1109/ICCET.2010.5485320. 